\title{
THE
}

\section{Benefits of Surfing for Children with Disabilities: A Pilot Study}

\author{
Cortney N. Armitano \\ University of Rhode Island \\ Emily D. Clapham \\ University of Rhode Island, eclapham@uri.edu \\ Linda S. Lamont \\ University of Rhode Island, lamont@uri.edu \\ Jennifer G. Audette \\ University of Rhode Island, jaudette@uri.edu
}

Follow this and additional works at: https://digitalcommons.uri.edu/kinesiology_facpubs

\section{The University of Rhode Island Faculty have made this article openly available. \\ Please let us know how Open Access to this research benefits you.}

This is a pre-publication author manuscript of the final, published article.

Terms of Use

This article is made available under the terms and conditions applicable towards Open Access Policy Articles, as set forth in our Terms of Use.

\section{Citation/Publisher Attribution}

Armitano, C. N., Clapham, E. D., Lamont, L. S., \& Audette, J. G. (2015). Benefits of Surfing for Children with Disabilities: A Pilot Study. Palaestra, 29(3), 31-34. doi: 10.18666/PALAESTRA-2015-V29-I3-6912

Available at: http://dx.doi.org/10.18666/PALAESTRA-2015-V29-I3-6912 
Surfing For Children With Disabilities Pilot Study 1

\section{SURFING FOR CHILDREN WITH DISABILITIES PILOT STUDY \\ 2}

3

4

5

6

7

8

9

10

11

Benefits of Surfing for Children with Disabilities: A Pilot Study

12

Cortney N. Armitano, Emily D. Clapham, Linda S. Lamont, Jennifer G. Audette

13

University of Rhode Island

14

15

16

17

18

19

20

21

22

23 
Surfing For Children With Disabilities Pilot Study 2

Abstract

25 The purpose of this study was to assess the effectiveness of an eight-week surfing intervention

26 for 16 children with disabilities. The assessment procedure consisted of pre and post physical

27 fitness measures to determine the benefits of this intervention. Our results showed an overall

28 improvement in upper body strength (right: $\mathrm{P}=0.024$, left: $\mathrm{P}=0.022)$, core strength $(\mathrm{P}=0.002)$

29 and cardiorespiratory endurance $(\mathrm{P}=0.013)$. This research is the first of its kind, illustrating the

30 feasibility and effectiveness of a surfing intervention on improving the physical fitness of

31 children with disabilities.

32

Keywords: Aquatic, Ocean, Fitness

33

34

35

36

37

38

39

40

41

42

43

44

45

46 
Surfing For Children With Disabilities Pilot Study 3

\section{Benefits of Surfing in Children with Disabilities: A Pilot Study}

Of the 53.9 million school-aged children (aged 5 to 17) in the United States, about 2.8 million (5.2 percent) were reported to have a disability (Brault, 2011). Children with disabilities have the same activity requirements as all children, who are recommended to accumulate 60 minutes or more of moderate to vigorous physical activity throughout the day (World Health Organization, 2012; ACSM, 2010). Participation in sports and recreational activities provide opportunities for these children that promote inclusion, minimize deconditioning, optimize physical functioning, and enhance overall well-being (Murphy, Carbone, \& the Council on Children with disabilities, 2008). Despite the benefits, disabled children are more restricted in their participation, have lower fitness levels, and higher obesity levels than their able-bodied peers (Murphy, 2008). This limited participation also puts them at risk for secondary health problems later in life such as dyslipidemia, coronary artery disease, osteoporosis and diabetes (Fragala-Pinkham, Haley, and O’Neil, 2008; Hayden, 1998). Unfortunately, opportunities to participate in fitness and activity programs, whether for leisure, recreation, or competition, are limited (Murphy, 2008; Okagaki, Diamond, Kontos, \& Hestenes, 1998; Rimmer, Riley, Wang, Rauworth, \& Jurkowski, 2004).

Adapted aquatics programs offer necessary physical activity and educational programming to these children (Kelly \& Darrah, 2005; Koury, 1996) and the physical and psychosocial benefits are more pronounced than those reported for children without disabilities (Koury, 1996; FragalaPinkham, 2008; Haley, 2010). Research involving children with cerebral palsy determined that aquatic exercise improves muscle strength, cardiorespiratory function, and gross motor skills (Peganoff, 1984; Hutzler, Chacham, \& Bergman, 1998; Thorpe and Reilly, 2000). There are reports that carefully planned and implemented water activities can contribute to the 
Surfing For Children With Disabilities Pilot Study 4

70 psychosocial and cognitive development of a child with a disability (Yilmaz, Yanardag, Birkan

$71 \&$ Bumin, 2004; Kelly, 2005). Similar benefits could potentially be derived from surfing in the

72 ocean. Surfing is known to be highly aerobic and exercise intensities are high $(75 \%-85 \%$ of

73 maximal heart rate) (Mendez-Villanueva \& Bishop, 2005). There are several surf programs

74 offered to people with disabilities around the world (e.g., Surfers Healing, Ride-a-Wave, and the

75 Disabled Surfers Association in Australia), and they are quickly gaining popularity.

The present study was designed to determine whether a surfing program is beneficial by

77 assessing physiological characteristics of the children before and after completion of the

78 program. Surfing programs for children with disabilities are gaining popularity, however the

79 benefits of these intervention programs have not been formally studied. This pilot project

80 provides a preliminary exploration of the benefits of ocean surfing in children with disabilities by

81 assessing for physiological improvements.

82

\section{$83 \quad$ Participants}

\section{Methods}

This study was approved by the Institutional Review Board at the University of Rhode Island on March 22, 2012. Sixteen participants were recruited from the University of Rhode Island Adapted Physical Education class, Special Olympics Rhode Island and through word-ofmouth throughout the local community. There was a wide range of children with disabilities in this study which included intellectual and learning disabilities, Down syndrome, several Autism Spectrum disorders, Microcephaly, Global Developmental Delays, Dandy-Walker syndrome, heart defects, and hypothyroidism (Table 1). Individuals interested in participating in the study needed to meet the inclusion criteria of being between 5 and 18 years, diagnosed with a 
Surfing For Children With Disabilities Pilot Study 5

92 developmental, sensory, and/or physical disability, categorized by disability levels of mild to

93 severe by a parent and/or guardian report, cleared by a medical doctor, and have an informed

94 consent signed by their parent/guardian and an assent form signed by the participant.

\section{Materials}

This was a pilot study with an experimental study design utilizing pre and post fitness

97 testing measurements (variables) to assess the surfing intervention. The fitness tests used were

98 from the Brockport Physical Fitness Test Manual (Winnick \& Short, 1999; Cureton, 1994) which

99 is based on The Cooper Institute's Fitnessgram. The tests were selected to measure

100 cardiorespiratory endurance, flexibility, muscular strength and muscle endurance. A practice day

101 was completed to familiarize all the children with the testing procedures.

102 Procedures

Each child was paired with an adult instructor for one-on-one surfing instruction. The 104 surf instructors were given training on the program goals, skills and optimal learning style of 105 each child to encourage maximum progression and participation in the program (Clapham, 106 Armitano, Lamont \& Audette, 2014). The surf instruction consisted of a one-hour session, twice 107 a week, for eight weeks; the child practiced surfing skills during these sessions. Specifically, 108 children progressed from: 1) paddling, 2) balancing on a surfboard while sitting (Figure 1), 109 laying, kneeling or standing (Figure 2), 3) catching a wave and riding it into shore in the prone, 110 sitting, kneeling (Figure 3), or standing position, and 4) how to paddle back out through the wave 111 unassisted (Clapham et al., 2014). The skills were first practiced in a large group format, then the 112 child and their surf instructor would break off to practice their skills one-on-one beginning on 
Surfing For Children With Disabilities Pilot Study 6

113 land and then in the ocean (Clapham et al., 2014). The progression through the skills were based

114 on each child's individual pace of learning and the goals set by the surf instructors.

SPSS version 19 statistical software was used for the data analyses. Given the broad

116 variability in disabilities of our sample group we used a Shapiro-Wilk Test to examine the

117 normality of distribution for our measures. For the normally distributed data a repeated measures

118 multivariate analysis of variance (ANOVA) using two time points (pre and post) was employed

119 (sit and reach, modified Apley's scratch test and hand grip). Significance was based on an alpha

120 of 0.05 using a Bonferroni correction and a 95\% confidence interval. For the non-normally

121 distributed data (trunk lift, modified curl-up, isometric push-up, 20 meter pacer scores $\mathrm{P}<0.05$ )

122 we used the nonparametric Wilcoxon Signed Ranks Test for paired variables. All data are

123 presented as mean \pm standard error of the mean.

124

Results

Table 2 lists the experimental results of this study. In the normally distributed items, we 126 found significant increases in the grip strength in both hands and flexibility of the right arm as

127 measured by the Apley's scratch test. The Back Saver Sit-and-Reach for both left and right arms 128 remained unchanged. For the non-normally distributed data, we found significant improvements 129 in core body muscle strength and aerobic capacity of our sample group as measured by the 130 modified curl-up and cardiorespiratory endurance test employed. There were no significant 131 improvements in the trunk lift or the isometric push up over the eight weeks of surfing 132 instruction for this sample of children with disabilities. 
Surfing For Children With Disabilities Pilot Study 7

\section{Discussion}

The purpose of this study was to explore the effectiveness of a surfing intervention for children with disabilities through an assessment of physiological measurements including; balance, strength, endurance, flexibility, and cardiorespiratory endurance. Results indicated that this surf program improved numerous areas of physical fitness and is another activity that can be added to the repertoire of effective adapted aquatic exercise programs. There were significant improvements in the participants' upper-body strength, core strength, as well as cardiorespiratory endurance. In the upper extremities there were increases in grip strength and in the participants' range of motion. The Modified Apley's scratch test was used to indicate improvements in the participants' range of motion. These results are consistent with research by Peganoff (1984) who found lap swimming increased shoulder flexion $15^{\circ}$ and shoulder abduction $10^{\circ}$ in the their participants right upper extremity. These improvements could be attributed to carrying the surfboard, arm use during swimming, and the repetitive arm motion needed to paddle through the water.

We found a substantial increase in core body muscle strength in our participants. Research by Fragala-Pinkham et al. (2010) also reported similar improvements after aerobic aquatic exercise. The improvements that we reported for core strength and endurance should be underscored, and are particularly beneficial as children with disabilities typically show a limitation in postural control (Liao, Jeng, Lai, Cheng \& Hu, 1997). We found no improvements in the trunk lift or balance. The lack of improvement in the trunk lift could be attributed to a ceiling effect, because the majority of our participants obtained the maximum score prior to the surfing instruction. 
Surfing For Children With Disabilities Pilot Study 8

Most research indicates that children with disabilities have low levels of cardiorespiratory

156

157

158

159

160

161

162

163

164

165

166

167

168

169

170

171

172

173

174

175

176

177

endurance when compared with their abled bodied peers (Murphy, 2008; Hayden, 1998; Fernhall

$\&$ Pitetti, 2001). Therefore, one of the most important benefits of this surfing project was the increase in cardiorespiratory endurance. A review by Mendez-Villanueva and Bishop (2005) (2005) indicated that surfing was a highly aerobic activity and Fragala-Pinkham et al. (2008)

found improvements in cardiorespiratory endurance after a 14-week aquatic aerobic exercise intervention.

Anecdotally, many positive outcomes were reported to be observed from the surfing intervention. Researchers, surf instructors, and parents observed increased self-confidence, gains in social development by interacting with the volunteer surf instructors and other participants, and decreased anxiety. Some of these improvements, as seen in research by Clapham et al. (2014), included increased verbalization, excitement and motivation about physical activity, and improvements in surfing skills. Several outcomes of the program were also reported to carry over into other areas of the participants' lives including increased participation and improved performance in other physical activities such as adapted physical education classes, the Special Olympics and Unified Sports. These observations are concurrent with previous research that also found participation in the surf intervention aided the participants in acquiring the selfconfidence, social skills, and physical fitness necessary to increase their participation in organized sport and physical activity (Clapham et al., 2014). It is recommended that future research examines these reported improvements formally.

It will be of interest to determine if improvements in cardiovascular fitness in children with disabilities can impact on the secondary health problems they are at risk of experiencing. The results of this study indicate that a surfing intervention program is feasible as well as 
Surfing For Children With Disabilities Pilot Study 9

178 beneficial to improve the cardiorespiratory endurance, muscle strength, flexibility and range of 179 motion of children with disabilities. Based on the researchers' results and feedback from 180 participants and parents, it appeared as though the surf intervention was effective in improving 181 lives of children with disabilities. 
Surfing For Children With Disabilities Pilot Study 10

\section{Acknowledgements}

$18450 \%$ of the cost of the equipment rentals and all of the volunteers from the community and from

185 the University of Rhode Island's Kinesiology Department and Physical Therapy Department. 
187 ACSM's guidelines for exercise testing and prescription. (2010). Philadelphia, PA: Lippincott Williams \& Wilkins.

Brault, M. W. (2011). School-aged children with disabilities in U.S. metropolitan statistical areas: 2010. Retrieved December, 2, 2013, from http://www.census.gov/prod/2011pubs/acsbr10-12.pdf

192 Clapham, E.D., Armitano, C.N., Lamont, L., \& Audette, J.G. (2014). The ocean as a unique therapeutic environment: developing a surfing program. Journal of Physical Education Recreation and Dance: 85(4):8-14.

Cureton, K. J. (1994). The prudential fitnessgram technical reference manual. Dallas, TX: Cooper Institute of Aerobics Research.

Fernhall, B., Pitetti, K. (2001). Limitations to work capacity in individuals with intellectual disabilities. Clinical Exercise Physiology, 3, 176-185

Fragala-Pinkham, M., Haley, S. M., \& O'Neil, M. E. (2008). Group aquatic aerobic exercise for children with disabilities. Developmental Medicine \& Child Neurology, 50(11), 822-827.

Hayden, M. (1998). Mortality among people with mental retardation living in the United States: research review and policy application. Mental Retardation, 36, 345-359.

Hutzler, Y., Chacham, A., Bergman, U. (1998). Effects of movement and swimming program on vital capacity and water orientation skills of children with cerebral palsy. Developmental Medicine \& Child Neurology, 40(3), 176-181.

Kelly, M., Darrah, J. (2005). Aquatic exercise for children with cerebral palsy. Developmental Medicine \& Child Neurology, 47, 838-842. 
Koury, J. (1996). Aquatic Therapy Programming. Champaign, IL: Human Kinetics.

Liao, H. F., Jeng, S. F., Lai, J. S., Cheng, C. K., \& Hu, M. H. (1997). The relation between single standing balance and walking function in children with spastic diplegic cerebral palsy. Developmental Medicine \& Child Neurology, 39, 106-112.

Mendez-Villanueva A., \& Bishop, D. (2005). Physiological aspects of surfboard riding performance. Sports Medicine, 35(1), 55-70.

Murphy, N. A., Carbone, P. S. \& Council on Children with Disabilities. (2008). Promoting the participation of children with disabilities in sports, recreation, and physical activities. PEDIATRICS, 121, 1057-1061.

Okagaki, L., Diamond, K. E., Kontos, S. J., \& Hestenes, L. L. (1998). Correlates of young children's interactions with classmates with disabilities. Early Childhood Research Quarterly, 13, 67-86.

Peganoff, S. A. (1984). The use of aquatics with cerebral palsied adolescents. The American Journal of Occupational Therapy, 38, 469-473.

Rimmer, J. H., Riley, B., Wang, E., Rauworth, A., \& Jurkowski, J. (2004). Physical activity participation among persons with disabilities. American Journal of Preventative Medicine, 26(5), 419-425.

Thorpe, D. E., \& Reilly, M. (2000). The effect of an aquatic resistive exercise program on lower extremity strength, energy expenditure, functional mobility, balance and self-perception in an adult with cerebral palsy: a retrospective case report. The Journal of Aquatic Physical Therapy, 8(2), 18-24. 
Surfing For Children With Disabilities Pilot Study 13

229 Winnick, J., Short, F. (1999). The brockport physical fitness test manual. Champaign, IL: Human $230 \quad$ Kinetics.

231 World Health Organization. (2012). Global strategy on diet, physical activity and health:

232 physical activity and young people. Retrieved from http://www.who.int/dietphysicalactivity/factsheet_young_people/en/index.html.

234 Yilmaz, I., Yanardag, M., Birkan, B., Bumin, G. (2004). Effects of swimming training on 235 physical fitness and water orientation in autism. Pediatrics International, 46, 624-626. 
Table 1

Subject Characteristics

\begin{tabular}{|l|l|l|l|l|}
\hline ID \# & Gender & Age & Disability type and other health information & Disability level \\
\hline 1 & Male & 15 & Autism & Mild \\
\hline 2 & Male & 7 & Down Syndrome & Mild \\
\hline 3 & Male & 6 & Autism- non-verbal & Moderate/Severe \\
\hline 4 & Male & 10 & Autism-non-verbal & Moderate \\
\hline 5 & Female & 9 & $\begin{array}{l}\text { Global developmental delays: specifically } \\
\text { speech and motor skills }\end{array}$ & Mild \\
\hline 6 & Male & 13 & Autism & Moderate \\
\hline 7 & Female & 13 & Down syndrome, hypothyroidism & Moderate \\
\hline 8 & Male & 12 & $\begin{array}{l}\text { Hypoplastic left heart syndrome, Suffered from } \\
\text { several strokes at a young age }\end{array}$ & Moderate \\
\hline 9 & Male & 10 & Autism & Moderate \\
\hline 10 & Male & 10 & ADHD, learning disabilities (reading), asthma & Mild \\
\hline 11 & Male & 13 & $\begin{array}{l}\text { Autism (Asperger Syndrome), ADHD, Tourette } \\
\text { Syndrome }\end{array}$ & Moderate \\
\hline 12 & Female & 16 & Down Syndrome, Hypothyroid & Moderate \\
\hline 13 & Female & 13 & $\begin{array}{l}\text { Autism (Asperger Syndrome), Obsessive } \\
\text { Compulsive Disorder, Anxiety Disorder }\end{array}$ & Moderate \\
\hline 14 & Male & 15 & Microcephaly, very low muscle tone & Severe \\
\hline 15 & Male & 5 & Sensory integration disorder, hyperkinetic & Moderate \\
\hline 16 & Female & 6 & Learning disabilities, dandy walker syndrome & Moderate \\
\hline
\end{tabular}




\section{Table 2}

Pre and Post Testing Results

\begin{tabular}{|c|c|c|c|c|}
\hline Test & Pre \pm SEM & Post \pm SEM & Improvements & Significance \\
\hline Grip strength (L) & $120.5 \mathrm{~N} \pm 25.5 \mathrm{~N}$ & $219.7 \mathrm{~N} \pm 23.1 \mathrm{~N}$ & $99.2 \mathrm{~N}$ & $\mathrm{P}=0.024^{\mathrm{a} *}$ \\
\hline Grip strength (R) & $120.0 \mathrm{~N} \pm 24.5 \mathrm{~N}$ & $225.6 \mathrm{~N} \pm 23.4 \mathrm{~N}$ & $105.5 \mathrm{~N}$ & $\mathrm{P}=0.022^{\mathrm{a} *}$ \\
\hline Isometric Push-Up & $\begin{array}{l}1: 28.8 \mathrm{~min} \pm \\
14.9 \mathrm{sec} .\end{array}$ & $\begin{array}{l}2: 00.4 \mathrm{~min} \pm \\
10.5 \mathrm{sec} .\end{array}$ & $31.6 \mathrm{sec}$. & $\mathrm{P}=\mathrm{N} \cdot \mathrm{S}^{\mathrm{b}}$ \\
\hline Modified Curl-Up & $16 \pm 5$ reps. & $27 \pm 6$ reps. & 11 reps. & $\mathrm{P}=0.002^{\mathrm{b} *}$ \\
\hline Trunk lift & $9.2 \mathrm{in} . \pm 0.8 \mathrm{in}$. & $9.8 \mathrm{in} . \pm 0.6 \mathrm{in}$. & $0.6 \mathrm{in}$. & $\mathrm{P}=\mathrm{N} \cdot \mathrm{S} .^{\mathrm{b}}$ \\
\hline $\begin{array}{l}\text { Back Saver Sit- } \\
\text { and-Reach (L) }\end{array}$ & $28.63 \mathrm{in} . \pm 2.50 \mathrm{in}$ & 29.06in. $\pm 2.39 \mathrm{in}$ & $0.4 \mathrm{in}$. & $\mathrm{P}=$ N.S. $^{\mathrm{a}}$ \\
\hline $\begin{array}{l}\text { Back Saver Sit- } \\
\text { and-Reach (R) }\end{array}$ & 29.0in. $\pm 2.6 \mathrm{in}$. & 29.0in. $\pm 2.4 \mathrm{in}$. & $0.0 \mathrm{in}$. & $\mathrm{P}=\mathrm{N} . \mathrm{S} .^{\mathrm{a}}$ \\
\hline $\begin{array}{l}\text { Modified Apley's } \\
\text { Scratch (L) }\end{array}$ & $12.5^{\circ} \pm 8.6^{\circ}$ & $14^{\circ} \pm 7.1^{\circ}$ & $1.5^{\circ}$ & $\mathrm{P}=0.095^{\mathrm{a}}$ \\
\hline $\begin{array}{l}\text { Modified Apley's } \\
\text { Scratch (R) }\end{array}$ & $10.8^{\circ} \pm 7.7^{\circ}$ & $14^{\circ} \pm 7.4^{\circ}$ & $3.18^{\circ}$ & $\mathrm{P}=0.034^{\mathrm{a}}$ \\
\hline 20-m PACER & 4 laps \pm 1 lap & 6 laps \pm 2 laps & 2 laps & $\mathrm{P}=0.013^{\mathrm{b} *}$ \\
\hline
\end{tabular}


Surfing For Children With Disabilities Pilot Study 16

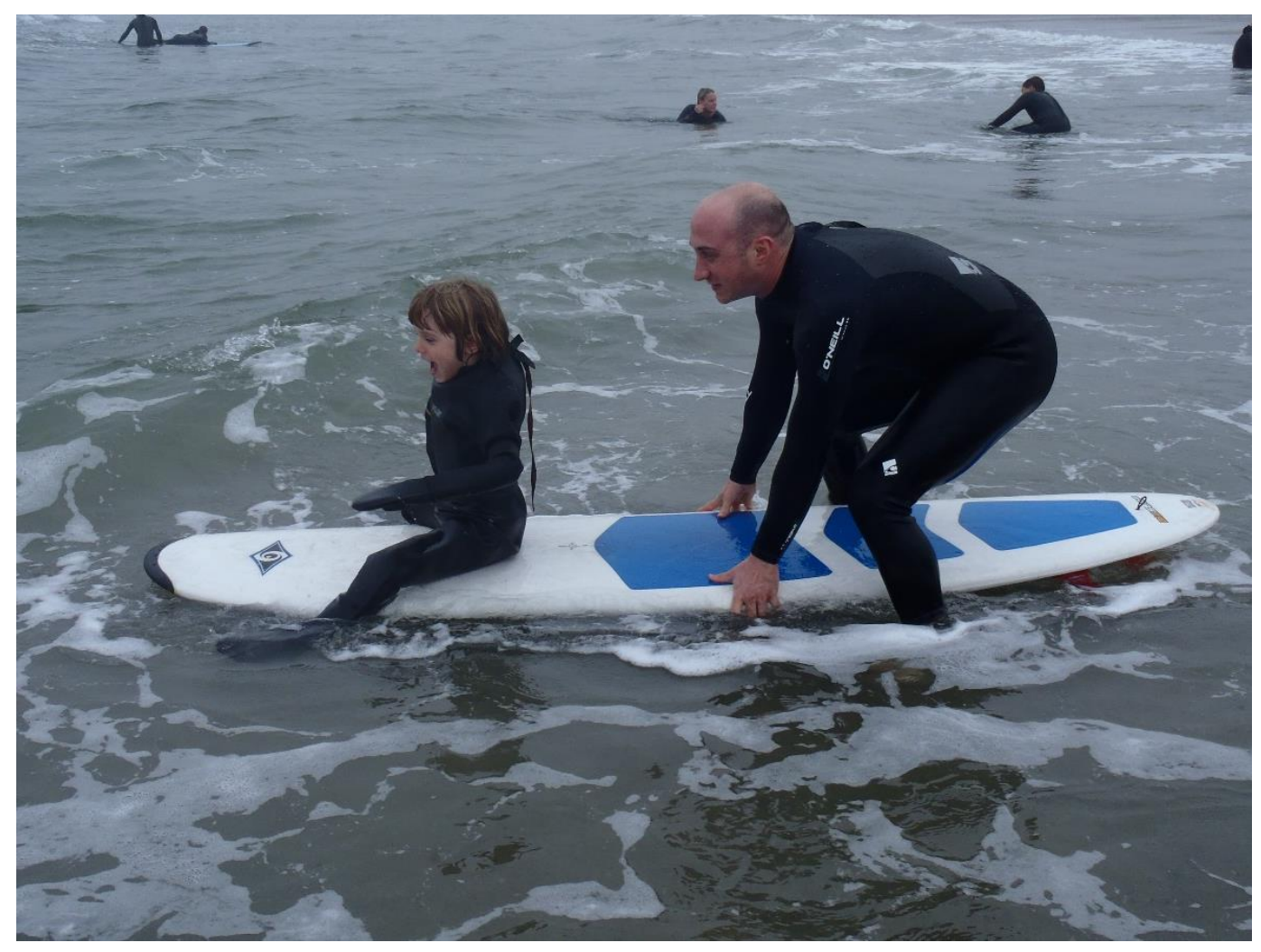

Figure 1 Balancing on the surfboard while sitting 
Surfing For Children With Disabilities Pilot Study 17

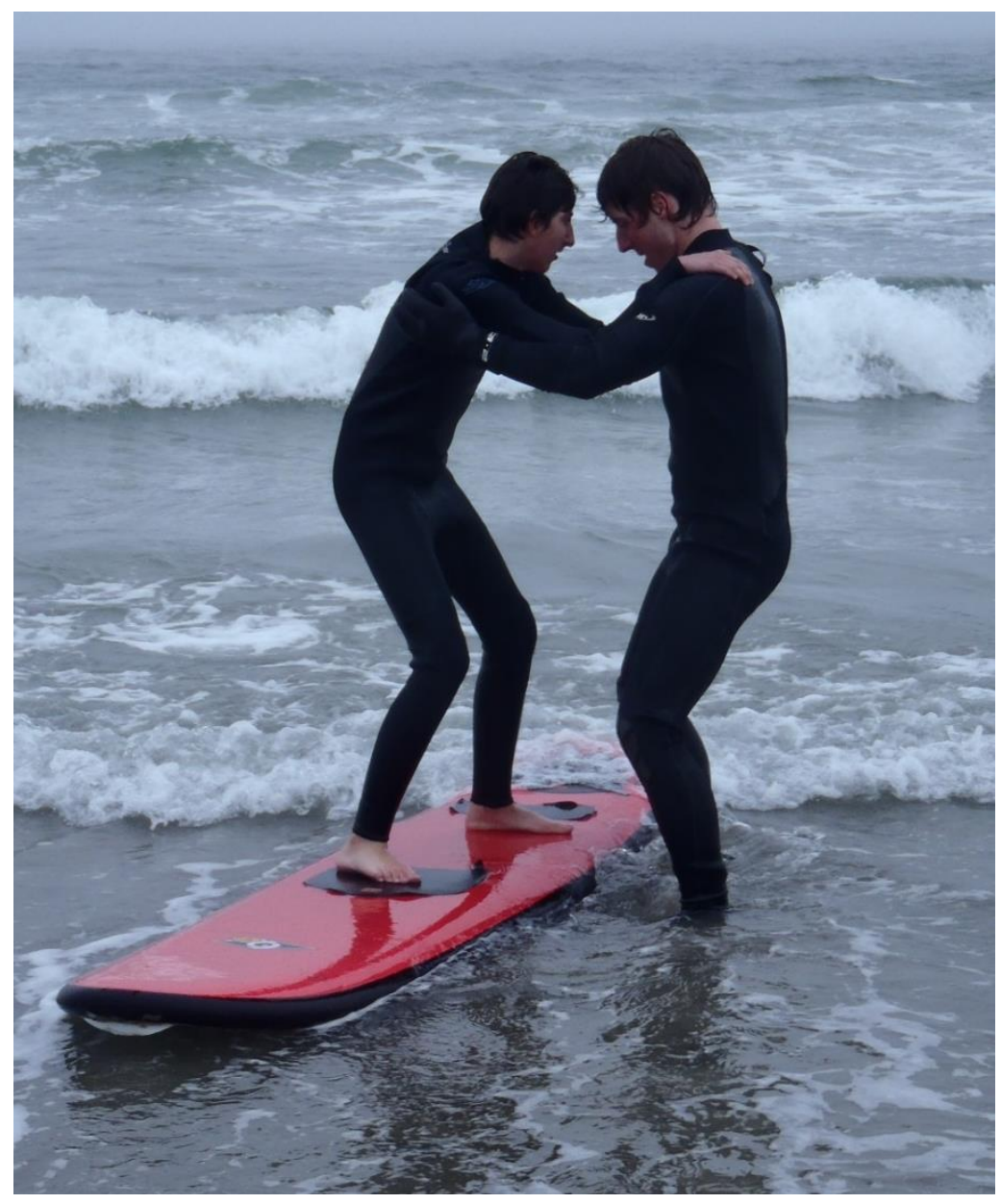

Figure 2 Balancing on the surfboard while standing 
Surfing For Children With Disabilities Pilot Study 18

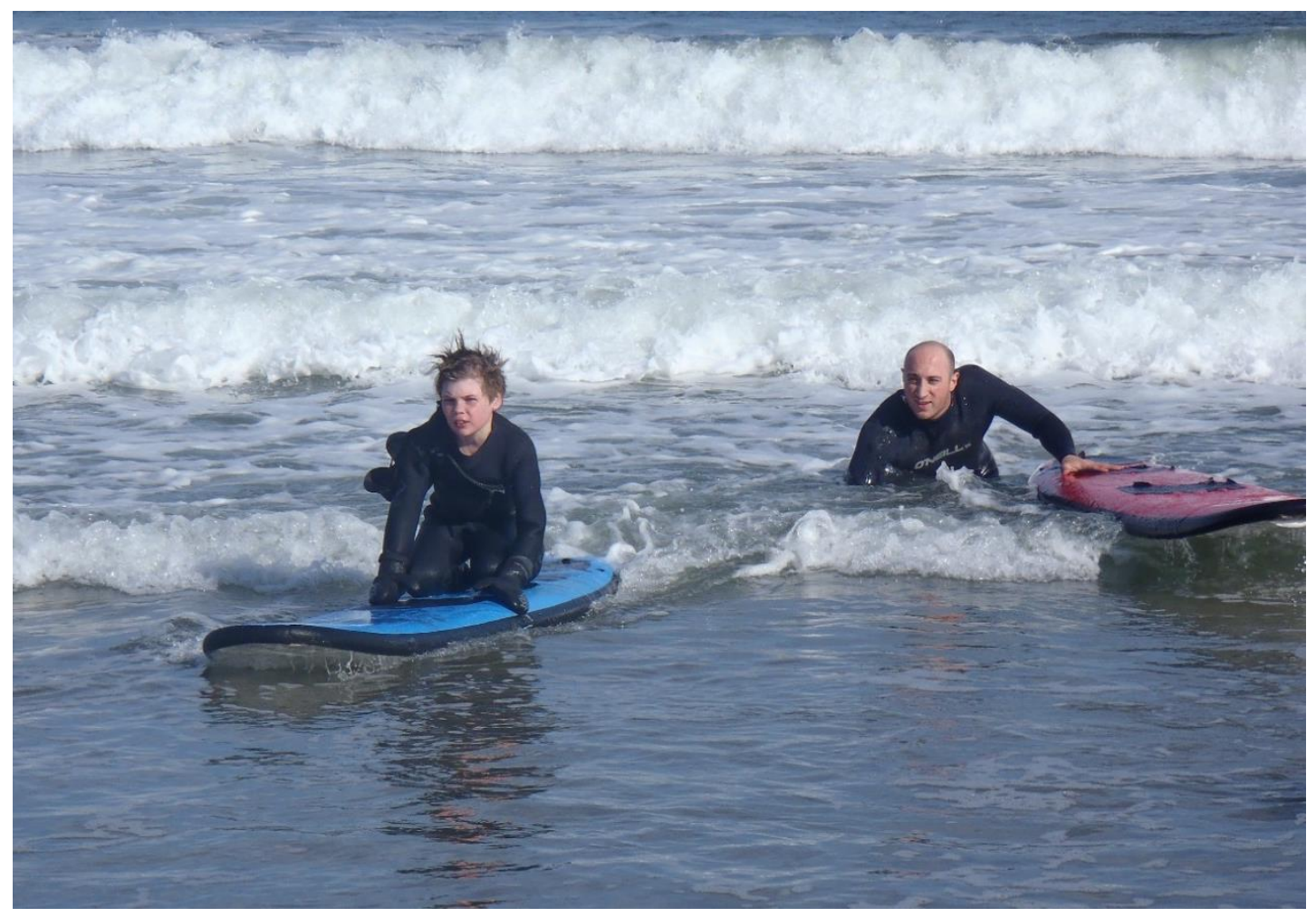

Figure 3 Riding a wave into shore while kneeling 